ISSN 2236-0859

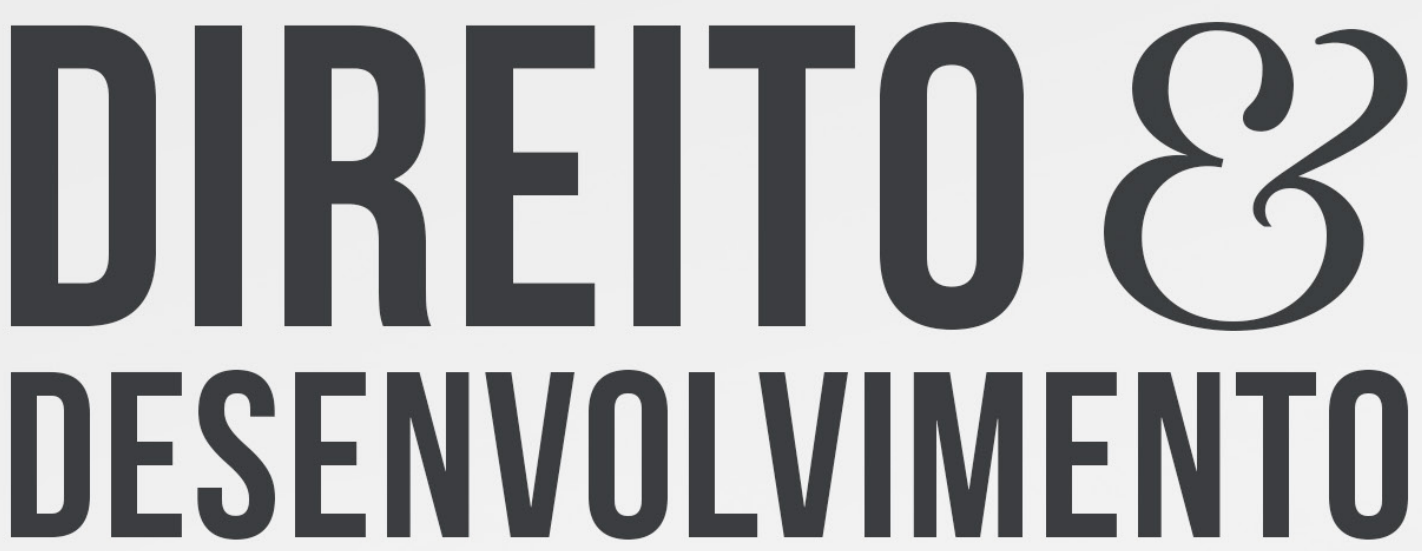

REVISTA DO PROGRAMA DE PÓS-GRADUAÇÃO EM DIREITO MESTRADO EM DIREITO E DESENVOLVIMENTO SUSTENTÁVEL

DIREITO AO DESENVOLVIMENTO: REFLEXÕES A PARTIR DO DIREITOECONÔMICO SOBRE O DESENVOLVIMENTO SUSTENTÁVEL

MARCELO TOBIAS DA SILVA AZEVEDO GIOVANI CLARK 


\title{
DIREITO AO DESENVOLVIMENTO: REFLEXÕES A PARTIR DO DIREITO ECONÔMICO SOBRE O DESENVOLVIMENTO SUSTENTÁVEL
}

\section{RIGHT TO DEVELOPMENT: REFLECTIONS FROM ECONOMIC LAW ON SUSTAINABLE DEVELOPMENT}

Recebido: 20/07/2018

Marcelo Tobias da Silva Azevedo ${ }^{1}$

Aprovado: 12/12/2019

Giovani Clark ${ }^{2}$

\begin{abstract}
RESUMO:
O conceito de desenvolvimento carrega uma carga de expectativa de melhoria das condições socioeconômicas da sociedade. Todavia, na década de 1960, o desenvolvimento era visto como crescimento modernizante em face da evolução da industrialização e foi incapaz desconcentrar a riqueza produzida e preservar os bens da natureza. Incorporou-se assim a sustentabilidade ao conceito de desenvolvimento, todavia ainda carente de precisão. $\mathrm{O}$ trabalho tem como objeto realizar a revisão bibliográfica dos conceitos de desenvolvimento e sustentabilidade, a partir das contribuições de Ignacy Sachs e de José Eli da Velga. E acrescenta, ainda, às lições de Direito Econômico sobre Direito do e ao desenvolvimento, proferidas pelo Professor Washington Peluso Albino de Souza, a fim de concluir que a Constituição brasileira de 1988 impôs o Direito ao Desenvolvimento, necessariamente sustentável, enquanto dever estatal e social e um dos direitos garantidos aos cidadãos brasileiros.
\end{abstract}

Palavras-chave: Desenvolvimento. Crescimento Modernizante. Sustentabilidade. Responsabilidade intergeracional.

\begin{abstract}
:
The development concept carries a load of expectation of improving the socioeconomic conditions of society. However, in the 196os, development was modernizing growth in the face of the evolution of industrialization and it was unable to deconcentrate the wealth produced and preserve environmental goods. Thus, sustainability has been incorporated into the concept of development, although still lacking in precision. The work aims to carry out the bibliographic review of the concepts of development and sustainability, based on the contributions of Ignacy Sachs and José Eli da Velga. He also adds the lessons of Economic Law on Law and Development, given by Professor Washington Peluso Albino de Souza, to conclude that the Brazilian Constitution of 1988 imposed the Right to Development, which is necessarily sustainable, as a

1 Mestre em Direito Público pela PUC-MG. Especialista em Gestão do Ambiente e Sustentabilidade pela FGV. Atualmente é vicepresidente do Instituto Brasileiro de Direito Minerário, membro da União Brasileira da Advocacia Ambiental e do Instituto dos Advogados de Minas Gerais. É coordenador e professor da pós-graduação em Direito da Mineração no CEDIN e professor na UNIBH. Advogado. Email: marcelotsazevedo@gmail.com

2 Doutor, Mestre e Graduado em Direito pela Universidade Federal de Minas Gerais. Professor da Pontifícia Universidade Católica de Minas Gerais nos cursos de Graduação e Pós-Graduação (Mestrado e Doutorado) e da Faculdade de Direito da UFMG (Graduação). Email: giovaniclark@gmail.com
\end{abstract}


state and social duty and one of the rights guaranteed to Brazilian citizens.

Key words: Development. Modernizing growth. Sustainability. Intergenerational Responsibility.

\section{INTRODUÇÃO}

O desenvolvimento é uma aspiração social e abrange uma carga de expectativa de melhoria das condições socioeconômica da sociedade. Entretanto, mesmo assentado na premissa de evolução, há uma dificuldade de se assentar o próprio conceito de desenvolvimento, ou seja, qual conjunto de situações poderiam ser englobadas no conceito e como se poderia medir a melhoria das condições sociais, econômicas, culturais, tecnológica. Desta feita, intenso debate teórico nas diversas ciências vem sendo desenvolvido desde a década de 1960, do século passado, no intuito de alinhar a ideia de desenvolvimento com a melhoria mensurável da qualidade de vida das inúmeras e discrepantes formas de sociedades.

Até a década de 1960, o desenvolvimento era tratado como crescimento econômico, que seria medido por índices de incremento da produção de bens e serviços, como o aumento da renda per capita ou do Produto Nacional Bruto. Havia associação nítida do desenvolvimento com o processo de industrialização, que nas nações chamadas de desenvolvidos representou, no quadro geral e a longo prazo, uma melhoria das condições de vida da população.

Entretanto, o fator de industrialização, enquanto crescimento econômico e melhora das condições de vida, não teve a mesma relação proporcional nas nações de industrialização tardia, como o Brasil. O crescimento não foi acompanhado da eliminação da pobreza extrema ou da ruptura de uma situação de desigualdade significativa entre as classes sociais, além de acarretar destruição dos bens da natureza. Em outras palavras, o crescimento econômico não foi suficiente para romper o desequilíbrio estrutural nas nações de industrialização retardada, hoje periféricas e semiperiféricas, ou seja, foi apenas modernizante.

Diante da constatação da insuficiência do "crescimento modernizante" para a promoção da melhora da qualidade de vida em geral, o conceito de desenvolvimento e as políticas a ele associadas precisaram ser repensados. Surgiu, assim, outras teorias que sustentassem um conceito que, embora mantivesse alguma associação entre desenvolvimento e crescimento, não os tratassem como conceitos sinônimos.

Nessa linha, abriu-se o campo teórico para o surgimento de teorias críticas e pessimistas sobre a (in)capacidade de sustentar um crescimento com a disponibilidade de recursos naturais e a sua utilização (ir)racional pela humanidade, o que inseriu uma nova abordagem na análise do crescimento. O debate de preservação dos recursos naturais disponíveis teve elevado relevo na década de 1960. As primeiras pautas de discussão revelavam um conflito de interesse entre as nações desenvolvidos, preocupados com o colapso ambiental mundial, e as nações pobres e de reduzida industrialização, preocupadas com a tentativa das nações do norte global em impor certas dificuldades ao seu crescimento modernizante via a exploração de seus recursos naturais.

Certa conciliação, ainda não definitiva, fora obtida pela Comissão Mundial de Proteção ao Meio Ambiente e Desenvolvimento e fixada no Relatório Brundtland de 1987. O relatório foi responsável por fixar o conceito de desenvolvimento sustentável, como objetivo para todos as nações. Englobava, assim, a preocupação com a disponibilidade e uso racional dos recursos naturais, mas indicava a necessidade premente em reduzir a pobreza extrema e as desigualdades entre ricos e pobres. 
O conceito de sustentabilidade, que passou a fazer par ao conceito desenvolvimento, não carrega em si, igualmente, uma precisão teórica uniforme. Pelo contrário, é dotado de forte inclinação política e ideológica, e certa vagueza conceitual. Intensos debates, ainda em processo de amadurecimento, buscam definir contornos precisos de avaliação de seus resultados e possíveis políticas concretas possíveis de ser enquadradas no conceito.

Independentementedas dificuldades teóricas, oconceito de desenvolvimento sustentável foi incorporado aos ordenamentos jurídicos das nações, entre eles o Brasil. Alias, ele integra a Constituição brasileira de 1988 em seus comandos e nas premissas básicas de orientação do Poder Público; seja por meio da limitação ou orientação da competência legiferante; seja como premissas de validade das políticas públicas ou, em ultima ratio, como conceito orientador do controle jurisdicional dos atos públicos, emanados da função legislativa ou executiva; seja ainda, consequentemente, limitando e disciplinado o poder econômico privado em face da utilização dos bens da natureza

Considerando o seu conteúdo, que direcionará a norma jurídica (de origem difusa) de conteúdo econômico, ou seja, a política econômica, o estudo do desenvolvimento, integrado a sua vertente sustentável, é objeto do Direito Econômico, especialmente direcionado à busca da promoção de melhoria da qualidade de vida. Sob seu aspecto jurídico, o desenvolvimento sustentável se enquadra como um direito potestativo, incorporado aos ditames constitucionais.

Assim sendo, o trabalho tem como objeto realizar a revisão bibliográfica dos conceitos de desenvolvimento e sustentabilidade, a parir das contribuições de Ignacy Sachs e de José Eli da Velga. E acrescenta, ainda, às lições de Direito Econômico sobre Direito do e ao desenvolvimento, proferidas pelo Professor Washington Peluso Albino de Souza, a fim de concluir que a Constituição brasileira de 1988 impôs o Direito ao Desenvolvimento, necessariamente sustentável, enquanto dever estatal e social e um dos direitos garantidos aos cidadãos brasileiros.

\section{ALGUMAS TEORIAS SOBRE O CONCEITO DE DESENVOLVIMENTO}

O conceito de desenvolvimento suscita algumas divergências teóricas, em diversos campos das ciências. Para além do seu significado etimológico, a dificuldade em conceituar desenvolvimento está alocada na imprecisão de se definir um conceito que agregue diferentes perspectivas das nações e dos homens sobre desenvolvimento.

Inobstante a dificuldade de se obter um conceito uniforme, parece ser possível indicar algumas premissas básicas e comuns a um conjunto significativo de abordagens. $\mathrm{O}$ desenvolvimento incorpora em si um aspecto positivo, de incremento (no mínimo) quantitativo, que aponta no sentido da evolução. Não se encontra teóricos que indiquem o desenvolvimento, em si considerado, como uma vertente negativa. Ainda que se defenda que o desenvolvimento pode trazer como consequências aspectos negativos em determinada comunidade, há uma premissa de incremento que poderá resultar em efeitos diversos, inclusive efeitos não almejados, que não podem ser evitados ou inconcebíveis. Ademais, na visão Washington Peluso Albino de Souza (2017), introdutor do Direito Econômico no Brasil, o desenvolvimento é um "desequilíbrio positivo" (SOUZA, 2017, p. 399) viabilizado de forma planejada, sobretudo das políticas públicas.

Além disso, o conceito de desenvolvimento parece indicar uma aspiração. As nações e as pessoas almejam o desenvolvimento, ainda que não elas não sejam capazes de indicar com clareza o que ele pode verdadeiramente representar. 
José Eli da Velga (2010) se dedicou sobre a melhor forma de conceituar o desenvolvimento. Assim, o professor ensina que se utilizam três formas gerais para definir o conceito desenvolvimento, sendo as duas primeiras formas de conceituação mais simples e a terceira mais complexa. As formas mais simples consistem em tratar o desenvolvimento como crescimento econômico (igualando os dois conceitos) e tratar o desenvolvimento como uma ilusão, uma quimera ou manifestação ideológica (VELGA, 2010, p. 18). A terceira abordagem seria a superação e o resultado das duas anteriores.

Apesar de não ser objeto do trabalho, versar sobre todas as correntes de desenvolvimento, como foi claro e delimitado no objeto do artigo, alertamos a existência de outras linhas de pensamento, como por exemplo, da "alternativa ao desenvolvimento", na qual a visão é "desenvolver sem crescer" (Santos, 2002, p, 54), tendo assim uma direção distinção a visão, do desenvolvimento alternativo a grosso modo "adotada" pela ONU em seus documentos e pela constituição de 1988.

Por último, e ao contrário da visão de desenvolvimento alternativo, existem as propostas de alternativas ao desenvolvimento, que radicalizam a crítica à noção de crescimento, e passam a explorar alternativas pós-desenvolvimentistas. Defende-se aqui, por exemplo, que o crescimento econômico é impossível de sustentar sem destruir as condições de vida sobre a Terra. A produção econômica, portanto, deve partir de uma nova concepção de desenvolvimento, esclarece Santos (2002, p. 54), ou seja, um "desenvolvimento sem crescimento - melhoria qualitativa da base física econômico que se mantém num estado estável [...] dentro das capacidades de regeneração e assimilação do ecossistema”. As atividades econômicas precisam, então, desenvolver-se sem crescer (CLARK, et al, 2013, p. 291).

Dedicaremos às abordagens antagônicas, desenvolvimento como crescimento e desenvolvimento como mito, e a via conciliatória, do desenvolvimento como liberdade.

\subsection{0 conceito de desenvolvimento tratado como crescimento econômico}

$\mathrm{O}$ intenso debate que surgiu sobre o conceito de desenvolvimento se deve em parte por trata-lo como sinônimo de crescimento, até a década de 1960 (VELGA, 2010, p.19). Nesta década, a medida de desenvolvimento era o "crescimento modernizante" (BERCOVICI, 2005, p. 53), vinculado principalmente a industrialização.

A capacidade de transformar a biomassa em produtos e serviços, em grande escala e com velocidade superior ao consumo, foi capaz de produzir excedentes e riquezas. As nações (norte global) se tornaram ricas pela industrialização, com amplo acesso (ainda que não irrestrito) dos cidadãos ao benefício alcançado pelo crescimento econômico, apesar de parcela da população só possuir o mínimo existencial. Por outro lado, ainda na linha teórica de equiparação entre crescimento econômico e desenvolvimento, as nações que eram consideradas pobres ou em desenvolvimento, tinham seus destinos selados por não possuírem um parque industrial considerável.

O desenvolvimento atrelado ao crescimento, calcada na industrialização começou a perder o sentido no meado do século XX. As premissas teóricas construídas eram as seguintes: se excluía os elementos de distribuição (igualitária ou isonômica) das riquezas e capacidade da natureza em fornecer matéria prima era dada como ilimitada. E ainda, o desenvolvimento da sociedade seria alcançado com o processo de industrialização, resultando no crescimento.

Ao contrário, Velga explica que "foram surgindo evidências de que o intenso crescimento econômico ocorrido durante a década de 1950 em diversos países semi-industrializados não se 
traduziu necessariamente em maior acesso de populações pobres a bens materiais e culturais" (VELGA, 2010, p. 19). A industrialização tardia não mostrou o mesmo resultado para as nações pobres e ricas e tratar o desenvolvimento como crescimento deixou, então, de fazer sentido, inclusive devido as consequências perversas quanto a distribuição dos bens e serviços produzidos e a natureza.

A partir da década de 1990 a Organização das Nações Unidas (ONIU) passou a se dedicar intensamente à temática do desenvolvimento. Como consequência, o Programa das Nações Unidas para o Desenvolvimento (PNUD) lançou o Índice de Desenvolvimento Humano, na década de 1990. A partir da utilização do índice, o desenvolvimento não estava mais adstrito a aspectos medido exclusivamente pelo crescimento econômico, como o incremento da renda per capita ou do produto interno bruto da nação.

\subsection{A tese do mito do desenvolvimento: desenvolvimento como ilusão}

A vinculação do desenvolvimento a quimera ou ilusão foi muito difundida pela obra de Giovanni Arrighi (1997). A tese defendida pelo autor italiano se baseia na dificuldade de se apontar a possibilidade de alteração da situação das nações na hierarquia da economia capitalista mundial. Ele parte da observação da divisão das nações, a partir de um núcleo orgânico formado das nações centrais, uma periferia formada pelas nações pobres e uma semiperiferia das nações emergentes. A tese central é a impossibilidade de mudança significativas dessa hierarquia entre as nações, o que poderia ser comprovada por meio da análise do Produto Nacional Bruto e, portanto, o desenvolvimento seria uma ilusão (ARRIGHI, 1997, p. 217).

A posição do autor italiano é severamente criticada por José Eli da Velga (2010):

(...) não há sequer muita lógica em afirmar que o desenvolvimento não passa de ilusão porque até aqui foram muitos raros os saltos da semiperiferia para o centro. Mesmo que se admitisse o pressuposto de que o desenvolvimento poderia ser aferido pelo PNB per capita, essa constatação autorizaria, no máximo, a conclusão de que o processo de desenvolvimento só pode ser muito lento e demorado (VELGA, 2010, p. 22).

Outros autores defendem a tese de desenvolvimento como mito, usando outros critérios além do Produto Nacional Bruto. Rivero (2002) trabalha com a ideia de inviabilidade das nações subdesenvolvidas. O primeiro fator que o autor indica é um elemento histórico. Nas nações industrializadas a formação da identidade nacional precedeu a formação do Estado. Esse mesmo fenômeno não ocorreu nas nações subdesenvolvidas, cuja formação da autoridade estatal e do Estado antecipou ao surgimento de uma burguesia e de uma economia capitalista nacional unificadora (RIVERO, 2002, p.12).

Rivero (2002) indica uma combinação entre o vírus da miséria tecnológica e da explosão demográfica que inviabilizam as nações subdesenvolvidas. Uma combinação de exportação de bens de baixo valor agregado (e que tende a diminuir cada vez mais de valor), que não seria suficiente para produzir riqueza o suficiente para o incremento da população em expansão, tendo como consequência a inviabilidade das nações mais pobres pautadas pela exportação.

Outro autor sobre o mito do desenvolvimento é o saudoso Professor Celso Furtado (2001). A tese central da obra se baseia na ideia de que os padrões de consumo das nações altamente industrializadas não poderão ser acessíveis às grandes massas em rápida expansão que formam a periferia. Para Furtado, a ideia de mito possui um papel para a ciência: 
O mito congrega um conjunto de hipóteses que não podem ser testadas. Contudo essa não é a dificuldade maior, pois o trabalho analítico se realiza em um nível muito mais próximo da realidade. A função principal do mito é orientar, num plano intuitivo, a construção daquilo que Schumpeter chamou de visão do processo social, sem a qual o trabalho analítico não teria qualquer sentido (FURTADO, 2001, p. 7).

Para sustentar sua tese sobre o mito do desenvolvimento econômico, o Professor Celso Furtado (2001) defende que o traço do capitalismo atual é que ele prescinde do Estado. Como a estabilidade dos Estados quanto a expansão de suas economias dependem de transações internacionais, ditadas pelas empresas transnacionais, forma-se uma relação de poder entre as grandes empresas e os Estados (FURTADO, 2001, p. 32). Assim, ocorre uma transformação da função do Estado e a emergência de uma nova ordem política.

Para Furtado (2001, p. 68), a inserção das nações de economias periféricas no campo da ação internacional das grandes empresas está contribuindo para a modernização das burocracias estatais, com significativa autonomia. E, assim, conclui:

O crescente controle internacional das atividades econômicas dos países periféricos acarreta uma precoce autonomia do aparelho burocrático estatal. Frequentemente, esse aparelho é controlado de fora do país, mas por toda parte ele está sujeito a ser empolgado por grupos surgidos do processo político local. Não obstante, prevalece o sentimento de impotência que resulta da dependência em que se encontram as atividades econômicas fundamentais de centro de decisões externos ao país (FURTADO, 2001, p. 69).

Furtado (2001) defende, então, que não se pode aceitar que a hipótese de que o padrão de consumo das nações ricas tende a generalizar em escala planetária. A ideia de desenvolvimento originada dessa premissa, para Furtado, resulta na exclusão de grandes massas que vivem nas nações periféricas das benesses criadas pelo "desenvolvimento" pautado nesse modelo (FURTADO, 2001, p. 82). Dessa forma, tem-se a ideia que o "desenvolvimento econômico" pautado na premissa de que as nações pobres poderão desfrutar do padrão de vida das ricas é irrealizável. Na verdade, as nações periféricas ou semi perificas, caso continuem a copiar os padrões de consumo e a adotar modelos de "desenvolvimento" das nações ricas, bem como a perpetuação das trocas desiguais internacionais entre elas, não passarão de um quantitativo "crescimento modernizante", como bem ensina Gilberto Bercovici (2005, p. 53), sem preservação da natureza e mega concentração de riquezas.

\subsection{0 desenvolvimento na visão de Amartya Sen}

O autor indiano, vencedor do Prêmio Nobel de Economia de 1998, desenvolveu a ideia de busca pelo caminho do meio. O caminho do meio que afasta ao mesmo tempo a teoria de se equiparar o desenvolvimento e o crescimento, bem como a teoria que trata o desenvolvimento como uma quimera, algo inexequível.

A obra se pauta pela necessidade de reconhecer que o papel das diferentes formas de liberdade no combate às privações e opressões existentes no mundo. Para Sen (2000):

O crescimento econômico não pode sensatamente ser considerado um fim em si mesmo. O desenvolvimento tem de estar relacionado sobretudo com a melhora da qualidade de vida que levamos e da liberdade que desfrutamos. Expandir a liberdade que temos razão para valorizar não só torna nossa vida mais rica e desimpedida, mas também permite que sejamos seres sociais mais completos, pondo em prática nossas volições, interagindo com o mundo que vivemos e influenciando esse mundo (SEN, 200o, p. 29). 
A expansão da liberdade, conforme afirmado por Amartya Sen, é o fim e o meio do desenvolvimento (SEN, 20oo, p. 27). O crescimento econômico é muito importante como meio para promover a liberdade dos membros da sociedade, promovendo acesso a recursos indisponíveis para exercício de uma autonomia. A liberdade, ainda, depende de outros meios para seu exercício pleno, como o acesso a serviços básicos ou a direitos civis:

\footnotetext{
As liberdades não são apenas os fins primordiais do desenvolvimento, mas também os meios principais. Além de reconhecer, fundamentalmente, a importância avaliatória da liberdade, precisamos entender a notável relação empírica que vincula, uma as outras, liberdades diferentes. Oportunidades sociais facilitam a participação econômica. Facilidades econômicas podem ajudar a gerar abundância individual, além de recursos públicos para os serviços sociais (SEN, 2000, p. 25-26).
}

Para Sen (200o), não é possível auferir desenvolvimento se de alguma forma a liberdade dos membros da sociedade é tolhida. A liberdade poder ser afetada pela pobreza, como a falta de acesso aos recursos disponíveis ou oportunidades econômicas. Pode ser minimizada ainda pela tirania do Estado, representada pela negligência dos serviços públicos ou a interferência no exercício de direitos fundamentais.

\section{NOVO VIÉS DO DESENVOLVIMENTO: OS ANTECEDENTES HISTÓRICOS E DESDOBRAMENTOS DAS CONFERÊNCIAS INTERNACIONAIS DE PROTEÇÃO AO MEIO AMBIENTE}

A partir da década de 1990, as Organizações das Nações Unidas (ONU) intensificaram o foco na promoção do desenvolvimento das nações. Mesmo antes desse período um novo elemento passou a ser considerado para o desenvolvimento: o enfoque ambiental. O modelo de desenvolvimento entendido como crescimento modernizante indicava que para se atender as necessidades de nações mais pobres, os recursos naturais existentes não seriam suficientes. Contudo, é possível apontar algumas tentativas anteriores e intensificadas no início do século passado no sentido de estabelecer algum controle sobre a disponibilidade de recursos naturais.

O Congresso Internacional para Proteção da Natureza, realizado em Paris, em 1923, é um bom exemplo sobre a proteção focada no controle dos recursos naturais utilizados para a promoção do crescimento econômico.

Em 1968, o Conselho Econômico e Social da ONU sugeriu e a Assembleia Geral aprovou a realização de uma conferência internacional com o objetivo de evitar a degradação do meio ambiente (SILVA, 2002, p. 28). A realização da conferência, em 1972, teve repercussões diferentes entre diversas nações, causando maior estranheza nas nações em desenvolvimento e alguns com posição antagônica, como o Brasil (SILVA, 2002, p. 29). As nações com industrialização tardia ainda enfrentavam (e ainda enfrentam) dificuldades graves relacionadas a pobreza e atendimento de serviços públicos básicos à população. Geraldo Eulálio Silva relembra:

\footnotetext{
A dificuldade enfrentada pelos países em desenvolvimento era que a documentação e toda a filosofia da Conferência espelhava posições de países do hemisfério norte que, além do mais, dispunham, nas reuniões preparatórias, de especialistas, o que não ocorria com os países em desenvolvimento, obrigados, na maioria, a recorrer a seus diplomatas (SILVA, 2002, p. 29).
}

Apesar de todo o receio das nações em desenvolvimento, chegou-se a um documento final que, tem em seu mérito, o reconhecimento que os problemas ambientais das nações em 
desenvolvimento eram e continuam a ser dos problemas das nações industrializados (SILVA, 2002, p. 32). Entre os vários princípios definidos pela declaração redigida na conferência, destaca-se o princípio 11, que estatui:

\begin{abstract}
Princípio 11
As políticas ambientais de todos os Estados deveriam estar encaminhadas para aumentar o potencial de crescimento atual ou futuro dos países em desenvolvimento e não deveriam restringir esse potencial nem colocar obstáculos à conquista de melhores condições de vida para todos. Os Estados e as organizações internacionais deveriam tomar disposições pertinentes, com vistas a chegar a um acordo, para se poder enfrentar as consequências econômicas que poderiam resultar da aplicação de medidas ambientais, nos planos nacional e internacional3.
\end{abstract}

Após a Conferência de 1972, a ONU criou em 1983 uma Comissão Mundial sobre Meio Ambiente e Desenvolvimento. A dita Comissão elaborou posteriormente um documento oficial intitulado 'Nosso Futuro Comum”, mas conhecido como Relatório Brundtland, em homenagem a Presidente da Comissão Gro Harlem Brundtland, que tem no seu currículo a marca de ser a primeira ministra de meio ambiente a se tornar chefe do executivo de uma nação.

Geraldo Eulálio Silva (2002, p.34) destaca que o relatório "dá especial ênfase às consequências negativas da pobreza sobre o meio ambiente”. No relatório surge a primeira ideia de responsabilidade intergeracional, buscando-se a utilização dos recursos pelas gerações presentes, de modo a garantir o uso pelas gerações futuras. É o relatório, também, que sugere a realização de nova conferência, realizada no Rio de Janeiro em 1992.

Desde 1987, o conceito de desenvolvimento sustentável vem sendo repetido como mantra. Contudo sem políticas socioeconômicas e ambientais públicas e privadas eficazes no mundo da vida pelos diversos quadrantes do território terrestre.

\title{
4. A VERTENTE SUSTENTÁVEL DO DESENVOLVIMENTO
}

A definição do conceito sustentabilidade também carrega em si grande divergência teórica. Almejando um aprofundamento teórico, é preciso indicar as bases de construção conceitual e seus eventuais limites.

Há aqueles que defendam que inexiste conflito entre a conservação ambiental e o crescimento econômico (VELGA, 2010, p. 109). Ainda sobre o enfoque da conciliação há a defesa da tese de que o crescimento econômico só prejudicaria o meio ambiente "até um determinado patamar de riqueza auferida pela renda per capita” (VELGA, 2010, p. 110).

Uma segunda teoria caminha em sentido oposto. Utilizando da segunda lei da termodinâmica afirma que as atividades econômicas transformam a energia em formas de calor tão difusas que são inutilizáveis. E acrescenta ainda: "em algum momento do futuro a humanidade deverá apoiar a continuidade de seu desenvolvimento na retração, isto é, com o decréscimo do produto" (VELGA, 2010, p. 112).

Para uma linha cética, pautada na segunda teoria, haveria uma condição estacionária. O desenvolvimento seria pautado em uma melhoria qualitativa, como, por exemplo, a substituição de fontes de energia fóssil por energia limpa. E defendem ainda:

\footnotetext{
"a hipotética conciliação entre o crescimento econômico e a conservação da natureza não é algo que possa ocorrer no curto prazo, e muito menos de isolada, de certas atividades, ou em locais específicos. Por isso, nada pode ser mais bisonho que chamar de 'sustentável' esta ou aquela proeza" (VELGA, 2010, p. 113)
}

3 Disponível em: www.mma.gov.br/estruturas/agenda21/_arquivos/estocolmo.doc. Acessado em: 27 de jul. de 2017. 
Entre essas duas linhas teóricas, a primeira pautada na inexistência de conflito entre crescimento econômico e a conservação ambiental e a segunda pela estagnação do crescimento pela incapacidade de se obter recursos naturais suficientes na sua promoção, existe uma linha intermediária, ainda não tão evoluída.

A teoria linha intermediária se pautada pela construção política-ideológica que teve início com a Conferência de Estocolmo de 1972 e foi consagrada pela Conferência do Rio de Janeiro de 1992, com a adoção da linha de sustentabilidade produzida pelo Relatório Brundtland. Velga (2010) indica que um dos melhores autores que sustenta essa linha é Ignacy Sachs que "soube evitar simultaneamente o ambientalismo pueril, que pouco se preocupa com a pobreza e desigualdades, e o desenvolvimentismo anacrônico, que pouco se preocupa com as gerações futuras" (VELGA, 2010, p. 171). Ainda para Velga (2010), "a sustentabilidade ambiental é baseada no duplo imperativo ético de solidariedade sincrônica com a geração atual e de solidariedade diacrônica com as gerações futuras " (p. 172).

A premissa da sustentabilidade incorpora a ideia da solidariedade entre as gerações futuras e atuais, impelindo a buscar soluções triplamente satisfatórias no seu sentido social, econômico e ambiental. Afasta, portanto, o crescimento modernizante (BERCOVICI, 2005, p. 53), incapaz de gerar transformações na sociedade, sem alto custo aos bens ambientais.

\subsection{A proposta de Ignacy Sachs de desenvolvimento sustentável}

Na visão de Sachs (200o), o crescimento integra o conceito de desenvolvimento e é um dos seus fatores principais. Eles não são equivalentes, especialmente porque no crescimento a mudança é quantitativa, enquanto no desenvolvimento é qualitativa. A verdade é que o desenvolvimento tem sido exceção histórica, pois geralmente temos "crescimento modernizante", sobretudo nas nações periférica ou semiperiféricas, e o desejado do desenvolvimento sustentável não é obra espontânea da força do mercado (CHANG, 2004, p. 13), por autorregulação, mas fruto sim de intervenção estatal planejada (SOUZA, 2017, p. 379) no domínio econômico, social, ambiental e tecnológico.

Ignacy Sachs (2000) defende a construção de um modelo de desenvolvimento cujo aproveitamento dos recursos naturais ocorra de forma sustentável. As sociedades passadas foram fundamentadas na biomassa, uma vez que dependiam dela para a sua vida material (SACHS, 2000, 29). Nessa linha, não se busca a retomada ao passado, mas "a invenção de uma moderna civilização de biomassa". E completa: "O argumento é que tal civilização conseguirá cancelar a enorme dívida social acumulada com o passar dos anos, ao mesmo tempo que reduzirá a dívida ecológica" (SACHS, 2000, 30).

A aposta de Sachs (2000) está na evolução da ciência a fim de que faça a construção do novo paradigma social, mais justo, em termos de equilíbrio social, e com maior respeito à natureza. $\mathrm{O}$ avanço científico proposto criará tecnologias e ferramentas equilibrando a balança entre as nações industrializadas, com menor fonte de recursos naturais, e as nações pouco industrializadas, nos quais há maiores reservas ambientais geralmente.

O desenvolvimento sustentável proposto por Sachs (2000), então, passa pelo aproveitamento racional dos bens da natureza, bem como da superação de algumas premissas.

A primeira premissa é a superação do modelo de crescimento econômico. O conflito anterior a Conferência de Estocolmo polarizava duas posições, sendo daqueles que previam a abundância dos recursos naturais e daqueles que pregavam a catástrofe. Tais posições extremas foram descartadas na Conferência, surgindo alternativa média "entre o economicismo arrogante e o fundamentalismo ecológico" (SACHS, 200o, p. 52). O caminho do meio indicava 
que o crescimento econômico ainda era necessário, mas deveria ser instrumentalizado mais favoravelmente à sociedade e ao meio ambiente, de forma evitar a conversão única do capital da natureza ao PIB (SACHS, 20oo, p. 52).

A segunda premissa de superação é a do Mercado. A lógica liberal de mercado, pautada na eficiência proposta por Adam Smith de alocação de recursos, na opinião de Sachs, não é compatível com o desenvolvimento sustentável (SACHS, 2000, p. 55). A superação estaria na busca de um equilíbrio entre sociedade, Estado e Mercado, com as instituições externas ao mercado "como necessárias para fiscalizar e corrigir os seus excessos e deficiências" (SACHS, 200o, p. 56). Por sinal, Sachs (2000) defende que o planejamento se mostra como ferramenta indispensável para projetar e promover as estratégias do desenvolvimento sustentável (p. 56), como aliás defende o introdutor do Direito Econômico no Brasil, o saudoso Professor Washington Peluso Albino de Souza (2017).

Deve-se superar também o antagonismo norte-sul. Isso porque a premissa do desenvolvimento sustentável deve ocorrer em escala global, com estratégias complementares entre norte e sul. O autor defende que a ONU teria papel fundamental nessa integração da estratégia única e articulada e que ela tem obtido "sucesso" na promoção da conscientização ambiental (SACHS, 2000, p. 59).

Por fim, a consagração do modelo de desenvolvimento sustentável dependerá da superação da economia ecológica, catastrófica. Para Sachs (2000), é preciso retomar uma economia política, no sentido de "um planejamento flexível, negociado e contratual, simultaneamente aberto para as preocupações ambientais e sociais" (SACHS, 200o, p. 6o)

Inspirado pelas lições de Ignacy Sachs, Velga define que,

o desenvolvimento tem a ver, primeiro e acima de tudo, com a possibilidade de as pessoas viverem o tipo de vida que escolheram, e com a provisão dos instrumentos e das oportunidades para fazerem as suas escolhas. (...) Vai desde a proteção dos direitos humanos até o aprofundamento da democracia (VELGA, 2010, p. 81).

Deve-se ter em vista que o crescimento econômico privilegia a manutenção da esfera de dominação, nas nações e entre nações. Na linha de raciocínio exposta pelos autores que pretendem superar a premissa do desenvolvimento como crescimento e também afastam a linha ideológica de que o desenvolvimento é mera ilusão, o desenvolvimento é trabalhado na inversão da lógica do "crescimento modernizante", no "desequilíbrio positivo" que tende a minimizar os impactos negativos coletivos e maximizar o aproveitamento coletivo dos bens da natureza, da tecnologia e distribuição social dos bens e serviços produzidos.

A proposição de Sachs (2000), bem como de Sen (2000), é a definição de um conceito de desenvolvimento que promova justiça social, com graus variáveis de utilização planejada dos recursos naturais para atingir esse fim. Por promover uma justiça social e tendo como fim a dignidade humana, o desenvolvimento sustentável, no modelo proposto, portanto, está no fundamento do direito brasileiro, ou seja, é um dos princípios da ordem economica (art. 170, VI da CR) e um dos capítulos (art. 225 da CR) da ordem social da nossa Lei máxima de 1988.

\subsection{0 desenvolvimento sustentável enquanto princípio jurídico constitucional}

A perspectiva da responsabilidade intergeracional, após a sua consolidação no debate internacional sobre o desenvolvimento foi incorporada por diversos ordenamentos jurídicos. A Constituição da República de 1988 adotou no caput do art. 225 a responsabilidade entre gerações como o fundamento básico da proteção ao meio ambiente para a nação: "Todos têm 
direito ao meio ambiente ecologicamente equilibrado, bem de uso comum do povo e essencial à sadia qualidade de vida, impondo-se ao Poder Público e à coletividade o dever de defendê-lo e preservá-lo para as presentes e futuras gerações" (BRASIL, 1988).

Para José Adércio Leite Sampaio (2003) a responsabilidade intergeracional é "um princípio de justiça ou equidade que nos obriga a simular um diálogo com nossos filhos e netos na hora de tomar uma decisão que lhes possa prejudicar seriamente" (SAMPAIO; et al, 2003, p. 53). Antônio Augusto Cançado Trindade (1993, p. 171) nos relembra que o Relatório Brundtland está permeado de considerações sobre equidade e justiça social. Em sua opinião, o relatório indica pela eliminação da pobreza generalizada ou extrema, mas também nos indica a buscar padrões de vida que sejam compatíveis com os meios ecológicos disponíveis.

O desenvolvimento sustentável revela uma acentuada dimensão temporal; com efeito, um elemento essencial da sustentabilidade é a obrigação geral básica de voltarse para o futuro. No reconhecimento e na asserção das exigências de sobrevivência e dos princípios e valores comuns superiores e das responsabilidades comuns, pode-se testemunhar a noção em evolução no direito internacional contemporâneo segundo a qual 'as obrigações e as capacitações não são atributos únicos dos Estados, mas são atinentes em primeiro ligar e sobretudo aos seres humanos e aos povos (TRINDADE, 1993, p. 173).

O direito ao ambiente ecologicamente equilibrado, incorpora a premissa do desenvolvimento sustentável, e cria obrigações públicas e privada que extrapolam a premissa temporal do presente, informando pela necessidade de buscar a efetivação dos direitos fundamentais as gerações atuais e futuras.

\section{DIREITO AO DESENVOLVIMENTO E DIREITO DO DESENVOLVIMENTO: NA VISÃO DO DIREITO ECONÔMICO}

O desenvolvimento é um dos objeto das normas que compõe o Direito Econômico, ou seja, o dito ramo do Direito possui como objeto o tratamento jurídico das políticas econômicas (SOUZA, 2017, p. 24-25), sejam elas públicas e privadas, inclusiva as voltadas ao desenvolvimento concomitante socioeconômico, tecnológico, ambiental, cultural de forma plural e democrática a fim concretizar os comandos constitucionais e seus ditames de justiça. Para sustentar essa afirmação, relembra-se que para o Direito Econômico "a busca da realização da justiça exige que a realidade econômica, no estágio atual da vida social, seja tratada além dos limites dos conflitos privados entre si, ou destes em confronto com os interesses públicos" (SOUZA, 2017, p. 24). É o Professor Washington Peluso Albino de Souza (2017, p. 23) que nos ensina que o Direito Econômico assegura a defesa e harmonia dos interesses individuais e coletivos.

O debate sobre o desenvolvimento das nações é provocado especialmente pela ONU, que indica os elementos que se incorporam nos ordenamentos jurídicos das nações. Para o Professor Washington Peluso Albino de Souza, o desenvolvimento deve ser avaliado em sua natureza de "fato social" (SOUZA, 2017, p. 399). O tratamento sobre o sentido jurídico do desenvolvimento encontrará as suas balizas, tanto no âmbito interno como externo, nas normas de conteúdo de política econômica.

As lições de Direito Econômico que nos indicarão as premissas teóricas para divisão do direito ao desenvolvimento e o direito do desenvolvimento.

O direito ao desenvolvimento é visto como uma potencialidade, um direito potestativo visto como pela ótica da "prosperidade" e pela "melhoria da qualidade de vida" (SOUZA, 2017, p. 40o), a que terá acesso todos os homens, quer como cidadãos das nações, quer como membros 
das tribos primitivas (SOUZA, 2017, p. 40o). Ainda segundo o Professor Washington Peluso Albino de Souza "em princípio, cabem-lhe os mesmos direitos ao conhecimento, ao mesmo tipo de valores sobre os elementos fundamentais da vida, portadores que são do referencial comum que os caracteriza como homens integrantes da comunidade" (SOUZA, 2017, p. 400).

Por sua vez, o direito do desenvolvimento "trata das normas jurídicas destinadas a garantir aquelas conquistas, integrando-se na vida dos homens e das nações, pela sua inclusão no ordenamento jurídico, quer internacional, quer nacional" (SOUZA, 2017, p. 401). Cuida-se das normas sobre as medidas de política econômica objetivando modelos de vida a sociedade. Assim sendo, o direito ao desenvolvimento é voltado a sua busca nas nações periféricas e semiperiféricas, já o direito do desenvolvimento é destinado à sua manutenção (riqueza) nas nações desenvolvidas.

\subsection{0 desenvolvimento sustentável como direito ao desenvolvimento sustentável}

O direito ao desenvolvimento possui, portanto, uma carga de aspiração, conteúdo de norma diretiva que deve ser buscado entre os objetivos gerais do Estado. Nos moldes da Constituição brasileira de 1988, em especial, no caput do art. 170, a ordem econômica tem como fim assegurar a todos existência digna (BRASIL, 1988). A existência digna, que ganhará relevos especiais, com a introdução do conceito de desenvolvimento sustentável. Paralelamente, o preâmbulo da Constituição de 1998 diz que o Estado Democrático de Direito brasileira deve assegura o desenvolvimento; a defesa do meio ambiente é ainda um dos princípios da ordem econômica (art. 170, VI da CR) e, portanto, um dos ditames necessários na construção e execução das políticas econômicas publicas e privadas em face do processo produtivo; além de ser garantido constitucionalmente o direito a um meio ambiente equilibrado a todos, seja das gerações presentes e futuras (art. 225 da CR), impondo assim dever dos segmentos sociais de assim agirem.

Assim sendo, a Constituição brasileira impõe o desenvolvimento sustentável a nação, visto pela ótica do Direito Econômico, como direito ao desenvolvimento, ou seja, um "desequilíbrio positivo", a fim de exterminarmos o dano ambiental irreversível (art. 225 da CR), a dependência cultural (art. 215 da CR) e tecnológicas (arts. 218 e 219 da CR,) a falta de direitos fundamentais (art. 6 da CR), a exploração econômica externa (art. 170, I da CR), etc.

Ademais, na visão do Professor Washington Peluso Albino de Souza, "a ideia de sustentabilidade, por seu turno, trouxe o conceito às considerações jurídicas do compromisso das gerações atuais com as gerações futuras, envolvendo a ação do homem com a natureza" (SOUZA, 2017, p. 406). E, assim, deve-se pensar como um direito ao desenvolvimento sustentável que preserva para todos, inclusive para as gerações futuras, também titulares do direito ao desenvolvimento, o direito ao meio ambiente ecologicamente equilibrado (art. 225, da Constituição).

É nessa linha que defende, Antônio Augusto Cançado Trindade:

Tendo isto em mente, podemos voltar nossa atenção à formação significativa, no plano global (Nações Unidas), do direito ao desenvolvimento como um direito humano, porquanto este último - como já indicado - está diretamente relacionado ao direito a um meio ambiente sadio (TRINDADE, 1993, p. 173)".

Não se pode, desta forma, desassociar o atendimento dos comandos da constituição, de forma a promover o desenvolvimento, que parte de uma premissa de liberdade como meio 
e como fim, defendido por Amartya Sen, promovendo a ruptura do equilíbrio que sustenta um estado de desigualdades, na linha de sustentação de Ignacy Sachs.

Contudo, não se pode pensar em um modelo de desenvolvimento que seja incompatível com a manutenção com o equilíbrio ecológico, inclusive na sua projeção para o futuro, bem como com a construção de uma sociedade plural, inclusive em seu modelo produtivo (CLARK; et al, 2013, p. 293).

\section{CONSIDERAÇÕES FINAIS}

Pensar o desenvolvimento como crescimento modernizante se mostrou insuficiente, especialmente considerando a manutenção do quadro social e ambiental desfavorável das nações de industrialização tardia ou não. A melhoria da qualidade de vida auferida nas nações, combinado com a defesa do meio ambiente, impõe uma intervenção estatal planejada no domínio econômico, social, ambiental, cultural e tecnológico a fim de resultar o "desequilíbrio positivo".

A partir do século XX o mundo teve que pensar premissas para o desenvolvimento diante do escandaloso quadro internacional de desigualdades sociais e destruição/exaltação dos bens da natureza. O debate foi impulsionado pela ONU, nas suas conferências mundiais. Posteriormente, o relatório Brundtland de 1987 foi responsável por fixar os ditames do desenvolvimento sustentável e, apesar das dificuldades de se direcionar objetivos concretos e mensuráveis, sua principal faceta é indicada pela responsabilidade intergeracional.

Assim, o documento "O Nosso Futuro Comum" fixa a promoção do desenvolvimento capaz de romper o desequilíbrio e as injustiças das relações sociais, com a eliminação da extrema pobreza, possibilitando o exercício de liberdades individuais, da autodeterminação dos povos. O relatório indica, ainda, a necessidade da incorporação de responsabilidade sobre a utilização dos bens da natureza, de forma a buscar formas de minimização da pressão sobre os recursos naturais, possibilitando a sua fruição as gerações presentes e futuras.

O desenvolvimento não pode ser pensado sem liberdade, por outro lado. A liberdade poder ser afetada pela pobreza, como a falta de acesso aos produtos e serviços essenciais ou oportunidades socioeconômicas, bem como pela dependência cultural e tecnológica. Pode ser minimizada, ainda, pela tirania do Estado e/ou poder econômico privado, que podem ser representadas pela negligência dos serviços públicos ou a interferência negativa no exercício de direitos fundamentais.

Por sua vez, a integração da sustentabilidade ao conceito de desenvolvimento está pautada pela construção de um novo paradigma social. $\mathrm{O}$ avanço científico pode propiciar tecnologias e ferramentas destinados a compatibilidade dos sistemas produtivos, distribuição social de bens e serviços e preservação/regate da natureza. E, portanto, virando as paginas das destruições e injustiças do crescimento modernizante.

A proposição de Sachs, bem como deSen, éa definição de um conceito de desenvolvimento que promova justiça social, com graus variáveis de utilização planejada dos recursos naturais para atingir esse fim. Por promover uma justiça social e tendo como fim a dignidade humana, o desenvolvimento sustentável, no modelo proposto, está no fundamento do direito brasileiro, ou seja, é apresentado como direito ao desenvolvimento, consagrados em diversos comandos constitucionais de nossa Lei máxima de 1988.

O desenvolvimento, enquanto, direito ao desenvolvimento, é um direito potestativo. Assim sendo, as ações estatais e privadas devem incorporar medidas políticas sociais, econômicas e tecnológicas que sejam capazes de romper as injustiças social e ambiental, 
especialmente quanto a eliminação da pobreza e a defesa do meio ambiente, dentre outras, a fim de se dar eficácia no mundo da vida a constituição brasileira de 1988.

\section{REFERÊNCIAS}

ARRIGHI, Giovanni. A ilusão do desenvolvimento. Petrópolis: Vozes, 1997.

BERCOVICI, Gilberto. Constituição econômica e desenvolvimento: uma leitura a partir da Constituição de 1988. São Paulo: Malheiros, 2005.

BRASIL. Constituição (1988). Constituição da República Federativa do Brasil. Brasília: Senado, 1988.

CHANG, Ha-Joon. Chutando a Escada: a estratégia do desenvolvimento em perspectiva histórica. Trad. Luiz Antônio Oliveira de Araujo. São Paulo: UNESP, 2004.

CLARK, Giovani. CORRÊA, Leonardo Alves. NASCIMENTO, Samuel Pontes do. Ideologia Constitucional e Pluralismo Produtivo. Revista da Faculdade de Direito da Universidade Federal de Minas Gerais, v. especial, 2013, p. 265-300.

FURTADO, Celso. O Mito do Desenvolvimento Econômico. $3^{\underline{a}}$ ed. São Paulo: Paz e Terra, 2001.

RIVERO, Oswaldo de. O mito do desenvolvimento. Os países inviáveis no século XXI. Petropólis: Vozes, 2002.

SACHS, Ignacy. Caminhos para o desenvolvimento sustentável. Rio de Janeiro: Garamond, 2000 .

SAMPAIO, José Adércio Leite; WOLD, Chris; NARDY, Afrânio. Princípios de Direito Ambiental: na dimensão internacional e comparada. Belo Horizonte: Del Rey; 2003.

SEN, Amartya. Desenvolvimento como liberdade. São Paulo: Companhia das Letras, 2000.

SANTOS, Boaventura de Sousa (org.). Produzir para Viver: os caminhos da produção não capitalista. Rio de janeiro: Civilização brasileira, 2002.

SILVA, Geraldo Eulálio do Nascimento e. Direito Ambiental Internacional. $2^{\underline{a}}$ ed. rev. e atual. Rio de Janeiro: THEX, 2002.

SOUZA, Washington Albino Peluso de. Primeiras Linhas de Direito Econômico. 6 6 ed. 2 a Tiragem. São Paulo: LTR, 2017.

TRINDADE, Antônio Augusto Cançado. Direitos Humanos e Meio Ambiente. Paralelo dos sistemas de proteção internacional. Porto Alegre: Sergio Antonio Fabris, 1993. 
THE WORLD COMMISSION ON ENVIRONMENT AND DEVELOPMENT. Our Common Future. Oxford University Press, 1987.

VELGA, José Eli da. Desenvolvimento Sustentável: o desafio do século XXI. Rio de Janeiro: Garamond, 2010. 